\title{
Phytochemical screening, cytotoxicity, mutagenicity, antimutagenicity, and protective potentials of the different solvent extracts from the air-dried leaves of Crescentia cujete Linn.
}

\author{
Merell P. Billacura ${ }^{1,2, *}$, Kelvin Kiram J. Pangcoga ${ }^{1}$ \\ ${ }^{1}$ Chemistry Department, College of Natural Sciences and Mathematics, Mindanao State University-Main Campus, Marawi City, \\ Lanao del Sur 9700, Philippines \\ 2Mamitua Saber Research and Technology Center, Mindanao State University-Main Campus, Marawi City, Lanao del Sur 9700, \\ Philippines
}

\section{A RT I C LE IN F O}

\section{Article history:}

Received 10 January 2017

Received in revised form

24 March 2017

Accepted 30 March 2017

\section{Keywords:}

Miracle fruit

Crescentia cujete

Artemia salina

\begin{abstract}
A B S T R A C T
Crescentia cujete Linn. is a fast-growing evergreen tree in the Philippines. Folklore says $C$. cujete Linn. has been used as an alternative medicine to treat ailments such as hematoma and tumors. In this study, air-dried leaves of $C$. cujete Linn. was prepared and partitioned using hexane, and ethyl acetate as solvents and was qualitatively assessed for the presence of phytochemical constituents. Secondary metabolites like flavonoids, tannins, reducing sugar, and steroids were observed in the preliminary phytochemical screening of hexane, ethyl acetate and aqueous extracts. Cytotoxicity of the different extracts were determined using brine shrimp lethality test (BSLT). Median lethal concentration ( $\mathrm{LC}_{50}$ ) of the hexane, aqueous, and crude ethanolic extracts were determined after 6 hours of exposure showing 572, 3048 and 220 ppm, respectively. Moreover, $\mathrm{LC}_{50}$ of the hexane, aqueous, and crude ethanolic extract, after 24 hours of exposure, were also determined showing $0,0.184$, and $6.47 \mathrm{ppm}$, respectively. The hexane, aqueous, and crude ethanolic extracts of $C$. cujete Linn. were also tested for its mutagenicity, antimutagenicity, and protective potentials using peripheral blood micronucleus test. The number of micronucleated polychromatic erythrocyte (MNPCE) observed from the mutagenicity test of hexane, aqueous, and crude ethanolic extract administered at a dose of $50 \mathrm{mg} / \mathrm{kg}$ and $100 \mathrm{mg} / \mathrm{kg}$ showed an average mean of 16.7,14.6 and 14.7, respectively, are lower compared to that of the positive control, methyl methanesulfonate (MMS), showing 49.5 number of MNPCE. Also, results for the antimutagenicity and protective potentials of hexane, aqueous, and crude ethanolic extract administered at a dose of $50 \mathrm{mg} / \mathrm{kg}$ and $100 \mathrm{mg}$ reduced the number of MNPCEs produced by the MMS.
\end{abstract}

(C) 2017 The Authors. Published by IASE. This is an open access article under the CC BY-NC-ND license (http://creativecommons.org/licenses/by-nc-nd/4.0/).

\section{Introduction}

Medicinal plants grow naturally around us. Over centuries, cultures around the world have learned how to use plants to fight illness and maintain health. These readily available and culturally important traditional medicines form the basis of an accessible and affordable health-care regime and are an important source of livelihood for indigenous and rural populations. Increasingly, medicinal species that reside in natural areas have received scientific

\footnotetext{
* Corresponding Author.

Email Address: merelljohn@gmail.com (M. P. Billacura) https://doi.org/10.21833/ijaas.2017.04.017

2313-626X/C 2017 The Authors. Published by IASE.

This is an open access article under the CC BY-NC-ND license

(http://creativecommons.org/licenses/by-nc-nd/4.0/)
}

and commercial attention. Evolution of diseases has led to the use of the medicinal prowess of plants.

Cancer is one of the most feared diseases of our time second to heart disease as a leading cause of death (Komarova et al., 2003). Cancer is a multistage process that evolves many years and is characterized by a series of chromosomal changes (Vogelstein et al., 1988). Normal cells are constantly subject to signals that dictate whether the cell should divide, differentiate into another cell or die. Cancer cells develop a degree of autonomy from these signals resulting in an uncontrolled growth and proliferation (Hemjadi, 2010). Most cancers are related to environmental, lifestyle, or behavioral exposures. Over time, more genes become mutated. This is often because the genes that make the proteins that normally repair DNA damage are 
themselves not functioning normally because they are also mutated. Statistical analysis says more like 5 or 6 mutations probably contribute to cancer.

In pursuit of finding remedies with this type of disease, researchers open the possibilities of synthesizing drugs from medicinal plants which are abundant throughout the world. Plants have a long history of use in the treatment of cancer (Hartwell and Bellizzi, 1982). The use of medicinal plants in healthcare by people of different culture and races across the globe is as old as the history of man (Egwaikhide et al., 2009). Many people nowadays depend on herbal remedies rather than buying synthetic drugs which is of high cost. Natural products once served humankind as the source of all drugs, and higher plants provided most of these therapeutic agents (Cooper, 1993). Philippines are blessed with different class of plants which are commonly used as a substitute to synthetic drugs. Crescentia cujete Linn. is one the plants which can be found here in Mindanao and some parts of Luzon and Visayas. It belongs to the family Bignoniaceae. According to some faith healers in Mindanao, this plant is believed to cure cough, cold, diabetes and other diseases. This study is designed to obtain a concrete proof about the beliefs of the medicinal prowess of Crescentia cujete Linn. The main interest of this study is the determination of the secondary metabolites, evaluation of toxicity, mutagenicity, antimutagenicity, and the protective potentials of the Crescentia cujete Linn.

\section{Methodology}

\subsection{Preparation of the extracts}

The Crescentia cujete Linn. leaves were collected at Lanuza, Surigao del Sur (9.1516 ${ }^{\circ}$ N, 126.0132 E). The Crescentia cujete Linn. leaves were washed with flowing water and air-dried. The leaves were tapped every day to avoid the production of molds. The airdried leaves were then cut into small pieces and then weighed using the top loading balance. About 685 grams of leaves were used for this study. The airdried leaves were then soaked with $95 \%$ ethanol for 72 hours. The soaked sample was filtered through vacuum filtration and concentrated in vacuo using the rotary evaporator. The concentrated ethanolic extract was then transferred into a beaker and was stored in a refrigerator.

\subsection{Solvent partitioning}

The crude ethanolic extract was weighed using the top loading balance. About 15 grams of crude ethanolic extract was added with $50 \mathrm{~mL}$ of $10 \%$ ethanol. The dissolved portion was then transferred to a separatory funnel. Fifty $\mathrm{mL}$ of hexane was added to the remaining crude ethanolic extract. This will be mixed in the separatory funnel with the previously dissolved portion. The mixture was shaken with frequent opening of the cartridge to expel evolved gases. Next, the solution was allowed to stand for several minutes until the complete separation of mixtures is observed. The bottom layer is the aqueous layer while the top layer is the organic layer. The top layer was removed using a pipette, and was placed in a beaker labelled with hexane extract (HE). This procedure was repeated until the top layer was completely separated and removed. The aqueous portion left inside the separatory funnel was partitioned using ethyl acetate, same as the procedure used in the partitioning using hexane. The organic layer at the top was extracted using the pipette and was transferred in a beaker labelled with ethyl acetate extract (EAE). The portion left in the separatory funnel was then placed in a beaker labelled with aqueous extract (AE). The obtained extracts from the partitioning process were then concentrated in vacuo using rotary evaporator.

\subsection{Phytochemical screening}

The phytochemical analysis of the crude ethanolic extract extracts was carried out to determine the presence of alkaloids, flavonoids, saponins, tannins, reducing sugars phytosterols with the procedures described by Tiwari et al. (2011).

\subsection{Detection of alkaloids (Dragendroff's Test)}

Two milliliters of the aqueous, hexane and ethyl acetate extracts were dissolved individually in $2 \mathrm{M}$ hydrochloric acid and filtered. Two milliliters of the filtrates were treated with 6 drops of Dragendroff's reagent. Formation of orange precipitate indicates the presence of alkaloids.

\subsection{Detection of flavonoids (Alkaline reagent Test)}

Two milliliters of the extracts were treated with few drops of $0.1 \mathrm{~N}$ sodium hydroxide solution. Formation of intense yellow color, which becomes colorless on addition of dilute acid, indicates the presence of flavonoids.

\subsection{Detection of saponins (Foam Test)}

Two milliliters of the extracts were shaken with $2 \mathrm{~mL}$ of distilled water. If foam produced persists for ten minutes it indicates the presence of saponins.

\subsection{Detection of tannins (Ferric Chloride Test)}

Two milliliters of the extracts were treated with 3-4 drops of 5\% ferric chloride solution. Formation of brown color indicates the presence of tannins and phenols.

\subsection{Detection of reducing sugars (Fehling's Test)}

Two milliliters of the extracts was added with $1 \mathrm{~mL}$ of both Fehlings $\mathrm{A}$, and $\mathrm{B}$ and was then shaken 
and heated in a water bath for ten minutes. Formation of a brick-red precipitate indicates the presence of reducing sugars.

\subsection{Detection of steroids (Salkowski's Test)}

Two milliliters of the extracts were treated with chloroform then added few drops of concentrated sulfuric acid, shaken and allowed to stand. Appearance of golden yellow color indicates the presence of steroids.

\subsection{Brine shrimp lethality test}

Each of the solvent extracts was weighed of approximately 0.05 grams and was then dissolved in $5 \mathrm{~mL}$ ethanol. The resulting solution served as the stock solution. $0.5,0.05$, and $0.005 \mathrm{~mL}$ was pipetted from the stock solution and was placed into three separate test tubes. It was then dried at room temperature. The dried solutions were then diluted with $5 \mathrm{~mL}$ of artificial seawater to obtain a concentration of 10, 100, and 1000 ppm, respectively. Five replicates for each concentration were prepared.

A plastic rectangular dish was divided into two unequal parts with little holes on its plastic divider. It was then filled with prepared artificial seawater. The large compartment was filled with brown brine eggs which was covered to keep it away from the light while the other smaller compartment was open and illuminated with light. Two days after, the hatched nauplii was pippeted from the illuminated compartment of the dish. Ten nauplii was pipetted and placed into each of test sample test tubes that contain different concentrations. A separate test tube served as the control tube, that contains $5 \mathrm{~mL}$ of artificial seawater, was also filled with ten nauplii. A small amount of yeast served as their food in each the test tube. The number of live nauplii was counted after 6 hours and 24 hours of keeping the test tube illuminated with a light bulb.

\subsection{Determination of the median lethal concentration (LC50)}

The $\mathrm{LC}_{50}$ was determined using probit analysis method described by Finney (1952). If deaths occur in the control vials, the data was corrected using Abbots formula (Eq. 1):

$$
\% \text { death }=\frac{\% \text { death in test vial }-\% \text { death in control vial }}{100-\% \text { death in control }} \times 100
$$

Graph was obtained by plotting \%deaths against concentration for each extracts. Then the $\mathrm{LC}_{50}$ was derived from the best-fit line obtained by linear regression analysis.

\subsection{Micronucleus test}

Micronucleus test for chromosomal aberration was conducted using peripheral blood. All procedures were performed according to the guidelines described and modified by OECD (1997) draft TG474.

Albino mice were used as test animal. Approximately 8-9 weeks old mice were purchased from a local pet shop in Iligan City, Philippines. The animals were acclimatized in laboratory condition for 2 weeks. They were fed with pellets and water throughout the acclimatization and experimental period. They were placed in a room at ambient temperature and subjected to regular light/dark cycle.

\subsection{Maximum tolerable dose}

The most bioactive extract was determined based on the brine shrimp lethality test results. A concentration of $10000 \mathrm{ppm}$ was used as the starting concentration. Five mice were used to determine the maximum tolerable dose of the extract. The most bioactive extract was administered via oral gavage. The dose that was given was $0.2 \mathrm{~mL} / 20 \mathrm{~g}$ body weight. The test mice were then observed over 24 hours. The maximum tolerable dose will be determined only if $50 \%$ of the population of the mice administered with the extract shows a sign of toxicity. The concentration of the most bioactive extract to be administered to the test mice was increased until at least $50 \%$ of the group treated will show signs of toxicity.

\subsection{Peripheral blood micronucleus test}

Test mice were randomly chosen for the experiment. A total of 27 mice were divided into nine groups which consist of three mice per group. The mice were treated for 7 days with 24 hour interval. Before treating, the mice were fasted from food and water for about 16 hours. Two hours after administration, the experimental mice were fed. Methyl methanesulfonate (MMS) was used as the positive control and distilled water and DMSO as the negative control. The nine groups are treated as follows:

- group 1 received distilled water for 5 days;

- group 2 received distilled water + dimethyl sulfoxide (DMSO) for 5 days;

- group 3 received 50,000 ppm of MMS for two days after treatment with distilled water for five days;

- group 4, and 5 received 5000 and 10000 ppm, respectively, of the hexane, aqueous, and crude ethanolic extracts for five days after administration with distilled water for two days;

- group 6 and 7 received 5000 and 10000 ppm, respectively, of the hexane, aqueous, and crude ethanolic extracts for five days after administration with MMS for two days.

- group 8 and 9 received 5000 and 10000 ppm, respectively, of the hexane, aqueous, and crude ethanolic extracts for five days before 
administration with MMS for two days with 24 hour interval.

The test mice were administered at a dose of 0.2 $\mathrm{mL} / 20 \mathrm{mg}$ body weight. Methyl methanesulfonate was administered at dose of $50 \mathrm{mg} / \mathrm{kg}$ body weight. The hexane, ethyl acetate, and aqueous extracts were administered at a dose of 50 and $100 \mathrm{mg} / \mathrm{kg}$ body weight respectively. Blood samples were then collected 32 hours after the last day of treatment. Blood was collected by cutting the tail of the mouse and a drop of blood was placed in a coded glass slide, smeared with a cover slip and then air-dried. The smeared preparation was then stained using Acridine Orange.

\subsection{Micronucleus scoring}

Micronuclei (MNi) are morphologically identical to but smaller than nuclei. They also have the following characteristics:

The diameter of $\mathrm{MNi}$ in human lymphocytes usually varies between $1 / 16$ th and $1 / 3$ rd of the mean diameter of the main nuclei, which corresponds to 1/256th, and 1/9th of the area of one of the main nuclei in a binucleated cell, respectively.

$\mathrm{MNi}$ are non-refractile and they can therefore be readily distinguished from artefact such as staining particles; $\mathrm{MNi}$ are not linked or connected to the main nuclei; MNi may touch but not overlap the main nuclei and the micronuclear boundary should be distinguishable from the nuclear boundary; $\mathrm{MNi}$ usually have the same staining intensity as the main nuclei but occasionally staining may be more intense.

Slides were coded and examined without the knowledge of the treatment (blind scoring) to avoid personal bias. To ensure that a cell was counted only once, the slide was carefully moved from top to bottom and left to right using the mechanical stage clip. Cells were scored by using 1000x (10x eyepiece and oil immersion objective) magnifications of Ken $\alpha$ Vision Light Microscope. Five slides per mouse were prepared and scoring was done from 1000 polychromatic erythrocytes (PCE) per slide. Statistical analyses of the results were undertaken using One-way Analysis of Variance (ANOVA) with Tukey test.

\section{Results and discussion}

\subsection{Phytochemical screening}

Phytochemical components such as alkaloids, flavonoids, saponins, tannins, reducing sugars, and terpenoids were determined in the hexane, ethyl acetate, and aqueous extracts of the air-dried leaves of Crescentia cujete Linn. using the procedure described by Tiwari et al. (2011). Results are summarized in Table 1.

As shown in Table 1, flavonoid is present in the air-dried leaves of $C$. cujete Linn. Flavonoids found in
C. cujete Linn. can act as antioxidants and protect cells of the body from the free radical damage; free radicals are reputed to damage cell and contribute to various health related problems.

Table 1: Phytochemical constituents of the hexane, aqueous, and ethyl acetate extracts of the air-dried leaves of Crescentia cujete Linn.

\begin{tabular}{cccc}
\hline Phytochemical & Hexane & Ethyl Acetate & Aqueous \\
\hline Alkaloids & $(-)$ & $(-)$ & $(-)$ \\
Flavonoids & $(-)$ & $(+)$ & $(++)$ \\
Saponins & $(-)$ & $(-)$ & $(++)$ \\
Reducing Sugars & $(++)$ & $(++)$ & $(+++)$ \\
Steroids & $(+)$ & $(+)$ & $(-)$ \\
Tannins & $(++)$ & $(+)$ & $(++)$ \\
\hline \multicolumn{7}{l}{$(+)$ trace, $(++)$ moderately present, $(+++)$ copiously present, $(-)$ absent }
\end{tabular}

Saponins, which is only present in the aqueous extract of $C$. cujete Linn. are known to serve as natural antibiotics and also boost energy (Lipkin, 1995). Saponins are also useful in reducing inflammation of the upper respiratory passage and also as foaming and emulsifying agent and detergents (Frantisek, 1998). Saponins in C. cujete Linn. may also serve as anti-inflammatory agent and as antibiotics in treating diseases and ailments.

Steroid is present in the hexane and ethyl acetate extracts of $C$. cujete Linn. Steroids are naturally occurring compounds that resemble cholesterol both in structure and biological function. Steroids, in free or esterified form are added to foods for their capacity to reduce the absorption of cholesterol in the gut and thereby lower blood cholesterol levels. Lastly, reducing sugar which exhibits copiously in the aqueous extract while traces of it can be seen in hexane and ethyl acetate extracts contain an antidiabetic property (Wang, 2016).

Tannin, which is present in all extracts of the $C$. cujete Linn., have a stringent properties that hasten the healing of wound, prevent decay and have antimicrobial activity (Chukwuma et al., 2010). Tannins and their compounds are also known to be responsible for preventing and treating urinary tract infections and other bacterial infections (Dong et al., 2004; Morton, 1981; Arbonnier, 2004). The presence of tannins in the leaves of $C$. cujete Linn. therefore, suggests that it may serve as a useful antibacterial agent. Tannins also act as antioxidants which protect cells from free radical damage causing aberrations of the cell (Chung et al., 1998).

\subsection{Brine shrimp lethality test}

Brine shrimp lethality test was used to explore the potential biochemical activity of the different extracts of the air-dried leaves of Crescentia cujete Linn. The test was performed using the procedure described by Meyer et al. (1982). Calculation of median lethal concentration ( $\mathrm{LC}_{50}$ ) was done using Probit analysis developed by Finney (1952).

The effectiveness or the concentration-mortality relationship of the plant is expressed as $\mathrm{LC}_{50}$. This represents the concentration of the extract that produces death in half of the test subjects after a 
certain time of exposure. This is then expressed by linear regression method from plotting percent (\%) mortality in probits against corresponding log of concentration. Table 2 shows the $\mathrm{LC}_{50}$ of the extracts after 6 and 24 hours of observation, respectively.

Table 2: Lethal concentration $\left(\mathrm{LC}_{50}\right)$ of the different extracts of the air-dried leaves of Crescentia cujete Linn. at 6 and 24 hours of exposure.

\begin{tabular}{|c|c|c|c|c|c|}
\hline \multirow{2}{*}{ Extracts } & \multirow{2}{*}{ Conc. (ppm) } & \multicolumn{2}{|c|}{ After 6 hours } & \multicolumn{2}{|c|}{ After 24 hours } \\
\hline & & \% Death & $\mathrm{LC}_{50}$ & \% Death & $\mathrm{LC}_{50}$ \\
\hline \multirow{3}{*}{ Hexane } & 10 & $16 \%$ & \multirow{3}{*}{572} & $100 \%$ & \multirow{3}{*}{0.00} \\
\hline & 100 & $30 \%$ & & $100 \%$ & \\
\hline & 1000 & $57 \%$ & & $100 \%$ & \\
\hline \multirow{3}{*}{ Aqueous } & 10 & $0 \%$ & \multirow{3}{*}{3,048} & $51 \%$ & \multirow{3}{*}{0.184} \\
\hline & 100 & $13 \%$ & & $60 \%$ & \\
\hline & 1000 & $6 \%$ & & $55 \%$ & \\
\hline \multirow{3}{*}{ Crude ethanolic } & 10 & $6 \%$ & \multirow{3}{*}{220} & $66 \%$ & \multirow{3}{*}{6.47} \\
\hline & 100 & $30 \%$ & & $90 \%$ & \\
\hline & 1000 & $80 \%$ & & $100 \%$ & \\
\hline
\end{tabular}

For the comparison of toxicity of extracts using $\mathrm{LC}_{50}$, the extract with the lowest $\mathrm{LC}_{50}$ value analyzed in 6 and 24-hour interval determines the most toxic and bioactive extract. In this study, the hexane, aqueous and crude ethanolic extracts of the air-dried leaves of Crescentia cujete Linn. were found to be the very toxic with respect to Artemia salina with an $\mathrm{LC}_{50}$ of 0, 0.184 and 6.47 ppm after 24 hours of exposure.

Table 3 suggests that the extracts are non-toxic to medium toxic after 6 hours against the nauplii, however, the extracts show high toxicity against the nauplii after 24 hours.

Table 3: Toxicity Classification of the Air-dried Leaves of Crescentia cujete Linn. according to Clarkson Toxicity Index

\begin{tabular}{ccccc}
\hline Extract & \multicolumn{2}{c}{ 6-hours } & \multicolumn{2}{c}{ 24-hours } \\
& LC $50, \mathrm{ppm}$ & Toxicity Profile & LC $_{50, \mathrm{ppm}}$ & Toxicity Profile \\
\cline { 2 - 4 } Hexane & 572 & Low & 0 & High \\
Aqueous & 3,048 & Non-toxic & 0.184 & High \\
Crude Ethanolic & 220 & Medium & 6.47 & High \\
\hline $\mathrm{LC}_{50}>1,000$ ppm are nontoxic, $\mathrm{LC}_{50}$ of $500-1000$ ppm are low toxic, $\mathrm{LC}_{50}$ of $100-500$ ppm are medium toxic, \\
\multicolumn{2}{c}{ while extracts with LC 50 of $0-100$ ppm are highly toxic (Clarkson et al., 2004) }
\end{tabular}

It only implies that all of the extracts of Crescentia cujete Linn. leaves is cytotoxic at any given concentration after 24 hours of exposure. On the other hand, the crude ethanolic extract showed the lowest $\mathrm{LC}_{50}$ after 6 hours of exposure with an $\mathrm{LC}_{50}$ of 220 ppm. Therefore, crude ethanolic extract of the Crescentia cujete Linn. leaves is the most cytotoxic extract after 6 hours of exposure.

\subsection{Micronucleus assay}

The maximum tolerable dose (MTD) of 100 $\mathrm{mg} / \mathrm{kg}$ was used as the highest dose for the experiment. The occurrence of micronucleated polychromatic erythrocytes (MNPCEs) in mouse peripheral blood was examined using the criteria set by Fenech (2000). Values are based on the average reading of five slides per mouse for three trials.

The peripheral blood micronucleus assay was employed to test the mutagenicity, antimutagenicity and protective effect of the hexane extract (HE), aqueous extract (AE) and crude ethanolic extract (CEE) from the air-dried leaves of Crescentia cujete Linn. A concentration of 5,000 and 10000ppm of the sample extracts were prepared for each treatment. Mutagenicity test of the albino mice was administered via oral gavage with sample extracts (HE, AE, and CEE) alone for 7 days. For protective potential and antimutagenicity test, sample extracts were administered before and after treatment with methane methylsulfonate (MMS). Studies conducted showed that MMS exhibits high degree of $\mathrm{N}$ alkylation in nucleobases which results in mutation on the cell (Eder et al., 1989). Protective potential test was carried out by treating the test mice with sample extracts for 5 days prior to induction of MMS for 2 days while antimutagenicity test was conducted by inducing the test mice with MMS for 2 days prior to treatment with sample extracts for 5 days. Positive control was treated with MMS while negative controls were treated with DMSO and distilled water for 7 days. The mice peripheral blood was collected after 36 hours of treatment.

For the mutagenicity test of hexane extract (HE) in Mus musculus occurrence of MNPCEs was observed in mice peripheral blood at two doses (Table 4). One-way ANOVA demonstrated that negative controls, DMSO and distilled water, are not significantly different from each other. The occurrence of MNPCEs in all dose level of hexane extract is significantly different from the negative control. This result implies that HE significantly increased the occurrence of MNPCEs. Nevertheless, compared with MMS administered at $50 \mathrm{mg} / \mathrm{kg}$, the occurrence of MNPCEs in mice treated with HE at the two doses is low for it to be considered as mutagenic. Comparing the two doses, $50 \mathrm{mg} / \mathrm{kg}$ showed higher occurrence MNPCEs with an average mean of 17.4. Occurrence of MNPCEs in mice peripheral blood is believed to have caused by the presence of phytochemicals in the plant sample which can be cytotoxic and caused the cell to exhibit chromosomal aberrations.

For the antimutagenicity test of the HE against chemical induced mutation of MMS in Mus musculus, results showed high reduction of MNPCEs compared 
to the positive control (MMS). This implies that the administration of HE to test mice after the induction of MMS proved to inhibit the action of the MMS to the cell therefore reducing the occurrence of MNPCEs. The occurrence of MNPCEs of 50 and 100 $\mathrm{mg} / \mathrm{kg}$ dosage are not significantly different. This implies that difference in dosage of the HE induced in the test mice does not affect or change the number of MNPCEs present. The trend shows the highest decrease in the frequency of MNPCES observed at the lowest dose $(50 \mathrm{mg} / \mathrm{kg})$ of $\mathrm{HE}$ with a mean MNPCEs frequency of 22.4 than 23.7 of $100 \mathrm{mg} / \mathrm{kg}$ dosage of HE. Both of these dosages also showed high decrease in the frequency of MNPCEs of with respect to the positive control.

Table 4: Average mean of MNPCEs of hexane extract

\begin{tabular}{ccc} 
& treatment \\
\hline Treatment & Dose $(\mathrm{mg} / \mathrm{kg})$ & Mean MNPCEs \\
\hline Mutagenicity & 50 & $17.4^{\mathrm{c}}$ \\
& 100 & $15.9^{\mathrm{c}}$ \\
Antimutagenicity & 50 & $22.4^{\mathrm{b}}$ \\
& 100 & $23.7^{\mathrm{b}}$ \\
Protective potential & 50 & $20.6^{\mathrm{b}}$ \\
DMSO & 100 & $21.2^{\mathrm{b}}$ \\
MMS & & $2.6^{\mathrm{d}}$ \\
\hline
\end{tabular}

Means having the same letters are not significantly different at $\alpha=0.05$. Values are based on the average reading of five slides per mouse for three trials. [DMSO $]=1 \%$ DMSO in $\mathrm{H}_{2} \mathrm{O}$.

The reason behind the reduction of occurrence of MNPCEs after treating the test mice with plant extract is because of the phytochemicals present in the sample itself. The HE was analyzed for the presence of secondary metabolites. It was observed that HE contains phytochemicals like tannins which has an antioxidant property which protects the cells from free radical damage (Chung et al., 1998). Because of this phytochemical, it greatly reduced the aberration of the cell caused by MMS.

The test for protective effect of $\mathrm{HE}$ against chemical induced mutation of MMS in Mus musculus also showed a high reduction in number of MNPCEs present compared to the positive control (MMS). One-way ANOVA of the HE suggests that they are significantly different from each other. The effect of decreasing the number of MNPCEs by HE is not dose dependent. Statistic implies that increasing the dose from $50 \mathrm{mg} / \mathrm{kg}$ to $100 \mathrm{mg} / \mathrm{kg}$ will not significantly increase the reduction of MNPCEs caused by induction of MMS. Nevertheless, the reduction of MNPCEs is still high at two doses, $50 \mathrm{mg} / \mathrm{kg}$ and $100 \mathrm{mg} / \mathrm{kg}$, with a mean MNPCEs frequency of 20.6 and 21.2 respectively compared to 49.5 mean MNPCEs frequency of the positive control, MMS. The mechanism of action of the protective potential test for the HE is the same from that of antimutagenicity test. Hence, they showed the same results. In the protective potential test, HE was first treated to the test mice prior to the administration of MMS. Because of this process, the phytochemicals present in the sample has already interacted with the cell of the test mice. Therefore, upon induction of the MMS, the cell has already been protected from the chromosomal aberration caused by the MMS. As shown in Table 4, comparing the occurrence of MNPCEs between the antimutagenicity and protective potentials, the protective potential test showed lower occurrence of MNPCEs. Therefore it implies that protecting the cell before induction of MMS is more effective than treating the cell after the induction of MMS.

For the mutagenicity test of AE, the occurrence of MNPCEs in two doses is significantly different from the negative control. This implies that $\mathrm{AE}$ has properties that could cause spontaneous chromosomal aberrations. However, compared to the occurrence of MNPCEs of the positive control, MMS, the two doses of $\mathrm{AE}$ is still low to be considered as mutagenic. On the other hand, statistical analysis shows that there is no significant difference between the two doses of AE. Therefore it simply implies that increasing the dosage of the $\mathrm{AE}$ administered will not significantly affect the number of MNPCEs formed.

For the antimutagenicity of $\mathrm{AE}$ of the air-dried leaves of $C$. cujete Linn., results found in Table 5 show that there is high reduction of MNPCEs with respect to the positive control (MMS). This implies that the AE contains phytochemicals like flavonoids, saponins, tannins and reducing sugars that can trap the $\mathrm{CH}_{3}$ carbocation released by the MMS.

Table 5: Average mean of MNPCEs of aqueous extract

\begin{tabular}{ccc} 
& treatment \\
\hline Treatment & Dose $(\mathrm{mg} / \mathrm{kg})$ & Mean MNPCEs \\
\hline Mutagenicity & 50 & $13.5^{\mathrm{c}}$ \\
& 100 & $15.7^{\mathrm{c}}$ \\
Antimutagenicity & 50 & $25.1^{\mathrm{b}}$ \\
& 100 & $24.8^{\mathrm{b}}$ \\
Protective potential & 50 & $22.9^{\mathrm{b}}$ \\
Distilled water & 100 & $22.7^{\mathrm{b}}$ \\
MMS & 50 & $5.5^{\mathrm{d}}$ \\
\hline
\end{tabular}

Means having the same letters are not significantly different at $\alpha=0.05$.

Values are based on the average reading of five slides per mouse for three trials.

One-way ANOVA suggest that there is no significant difference between the two doses of $\mathrm{AE}$ administered to the test mice. In Table 5, it can be observed that highest decrease in occurrence of MNPCEs is demonstrated by the highest dose $(100 \mathrm{mg} / \mathrm{kg})$ with a mean frequency of 24.8 compared with 49.5 mean MNPCEs frequency of the positive control (MMS).

The test for protective potential of the $\mathrm{AE}$ of the air-dried leaves of $C$. cujete Linn. also showed significant decrease in number of MNPCEs present after induction of MMS. This implies that protective potentials test can inhibit the action of the MMS by protecting the cells first before the MMS was introduced. One-way ANOVA demonstrated that there is no significant difference between the two doses of AE.

For the mutagenicity test of the crude ethanolic extract (CEE) from the air-dried leaves of $C$. cujete Linn, occurrence on MNPCEs was observed in mice peripheral blood at two doses (Table 6). The occurrence of MNPCEs in two doses of CEE is 
significantly different from the negative control (distilled water). This implies that CEE has the property which causes spontaneous chromosomal aberrations resulting to the occurrence of MNPCEs. Nevertheless, compared to the positive control (MMS) administered at $50 \mathrm{mg} / \mathrm{kg}$, occurrence of MNPCEs in mice treated with CEE at two doses is low to be considered mutagenic and not concentration dependent.

Table 6: Average mean of MNPCEs of crude ethanolic

\begin{tabular}{ccc} 
& extract treatment & \\
\hline Treatment & Dose $(\mathrm{mg} / \mathrm{kg})$ & Mean MNPCEs \\
\hline Mutagenicity & 50 & $15.0^{\mathrm{c}}$ \\
& 100 & $14.3^{\mathrm{c}}$ \\
Antimutagenicity & 50 & $24.3^{\mathrm{b}}$ \\
& 100 & $26.9^{\mathrm{b}}$ \\
Protective potential & 50 & $21.9^{\mathrm{b}}$ \\
Distilled water & 100 & $24.8^{\mathrm{b}}$ \\
MMS & 50 & $5.5^{\mathrm{d}}$ \\
\hline
\end{tabular}

Means having the same letters are not significantly different at $\alpha=0.05$. Values are based on the average reading of five slides per mouse for three trials.

For the antimutagenicity test of CEE from the airdried leaves of $C$. cujete Linn. against chemically induced mutation of MMS in Mus musculus, results show a high reduction of MNPCEs compared to the positive control (MMS). It clearly suggests that CEE also has the ability to inhibit the action of MMS because of the phytochemicals present in the sample. Statistic shows lower decrease in the frequency of MNPCEs observed at the higher dose $(100 \mathrm{mg} / \mathrm{kg})$ with a mean MNPCEs frequency of 26.9 compared with 49.5 mean MNPCEs frequency in the positive control.

The test for protective effect of the CEE against chemically induced mutation of MMS in Mus musculus shows a high reduction of MNPCEs with respect to the positive control, MMS, and is significantly different from each other. The reduction of MNPCEs is observed to be higher at $50 \mathrm{mg} / \mathrm{kg}$ with mean MNPCEs frequency of 21.9 compared with 49.5 mean MNPCEs frequency of the positive control (MMS).

For the mutagenicity of each sample extracts, occurrence on MNPCEs was observed in mice peripheral blood. It implies that all extract of the $C$. cujete Linn. causes chromosome aberrations of the cell. We can observe in Table 7 that there is significant difference in the occurrence of MNCPE in each extracts of the $C$. cujete Linn. We can observe that the hexane extract showed higher number in the occurrence of MNPCEs compared to our negative control, DMSO and distilled water.

We can conclude that hexane extract exhibits the mutagenic effect among the three extracts. Nevertheless, compared to the occurrence of MNPCEs exhibited by the chemically induced MMS, the mean frequency of MNCPEs in hexane is still low to be considered as mutagenic.

For the antimutagenicity of extracts of $C$. cujete Linn, results are shown in Table 8 which summarizes the mean frequency of MNPCEs occurrence. From the table, we can conclude that hexane extract showed higher reduction of occurrence of MNPCEs with respect to the positive control (MMS) which has a mean frequency of 49.5 It implies that among the three extracts, hexane extract is the most effective extract that could inhibit the chemically induced MMS. Based on the phytochemical screening done on all extracts of the C. cujete Linn. all of the extract showed presence of tannins and reducing sugars whereas AE and CEE contain flavonoids, saponins, in addition to tannins and reducing sugars. According to Chung et al. (1998), tannins act as an antioxidant which protects the cell from free radical damage. Probably these phytochemicals may also trap the $\mathrm{CH}_{3}$ carbocation released from MMS.

Table 7: Average mean of MNPCEs of mutagenicity treatment

\begin{tabular}{cc}
\hline Treatment & Mean MNPCEs \\
\hline Hexane extract & $16.7^{\mathrm{b}}$ \\
Aqueous extract & $14.6^{\mathrm{b}}$ \\
Crude ethanolic extract & $14.7^{\mathrm{b}}$ \\
Distilled water & $5.5^{\mathrm{c}}$ \\
DMSO & $2.6^{\mathrm{c}}$ \\
MMS & $49.5^{\mathrm{a}}$ \\
\hline
\end{tabular}

Means having the same letters are not significantly different at $\alpha=0.05$. Values are based on the average reading of five slides per mouse for three trials.

Table 8: Average mean of MNPCEs of antimutagenicity

\begin{tabular}{cc}
\hline \multicolumn{2}{c}{ treatment } \\
\hline Treatment & Mean MNPCEs \\
\hline Hexane extract & $23.1^{\mathrm{b}}$ \\
Aqueous extract & $25.0^{\mathrm{b}}$ \\
Crude ethanolic extract & $25.6^{\mathrm{b}}$ \\
Distilled water & $5.5^{\mathrm{d}}$ \\
DMSO & $2.6^{\mathrm{d}}$ \\
MMS & $49.5^{\mathrm{a}}$ \\
\hline Means having the same letters are not significantly different at $\alpha=0.05$. \\
Values are based on the average reading of five slides per mouse for three \\
trials.
\end{tabular}

Also for the protective potential (Table 9) of the extracts from the air-dried leaves of $C$. cujete Linn., we can infer that hexane extracts showed the highest reduction in occurrence of MNPCEs than the other extracts with respect to the positive control. Thus, protective potential test is more effective than the antimutagenic effect of the sample extracts.

Table 9: Average mean of MNPCEs of protective potential

\begin{tabular}{cc}
\multicolumn{2}{c}{ treatment } \\
\hline Treatment & Mean MNPCEs \\
\hline Hexane extract & $20.9^{\mathrm{b}}$ \\
Aqueous extract & $22.8^{\mathrm{b}}$ \\
Crude ethanolic extract & $23.4^{\mathrm{b}}$ \\
Distilled water & $5.5^{\mathrm{c}}$ \\
DMSO & $2.6^{\mathrm{c}}$ \\
MMS & $49.5^{\mathrm{a}}$ \\
\hline
\end{tabular}

Means having the same letters are not significantly different at $\alpha=0.05$. Values are based on the average reading of five slides per mouse for three trials.

Antimutagencity test was conducted by administering MMS prior to treatment with the sample extracts. Therefore, MMS may have already interacted with the cell before it was treated with sample's phytochemicals. On the other hand, protective potential test was conducted by administering the sample prior to induction of MMS. With this process, probably the sample's phytochemicals have already trapped the $\mathrm{CH}_{3}$ 
carbocation released by MMS prior to chromosomal aberration.

Table 10 shows the mean average of the MNPCEs formed in the mutagenicity, antimutagenicity and protective tests. Results show that $\mathrm{HE}, \mathrm{AE}$ and $\mathrm{CEE}$ have comparable effects towards trapping the $\mathrm{CH}_{3}$ carbocation released by MMS. Fig. 1 also that in this study, the mutagenicity, antimutagenicity and protective tests are not concentration dependent.
Table 10: The average mean of the number of MNPCEs in mutagenicity, antimutagenicity, and protective potentials of HE, AE and CEE of Crescentia cujete Linn.

\begin{tabular}{cccc}
\multirow{2}{*}{ Treatment } & \multicolumn{3}{c}{ MNPCE Frequency Mean } \\
\cline { 2 - 4 } & HE & AE & CEE \\
\hline Mutagenicity & 16.7 & 14.6 & 14.7 \\
Antimutagenicity & 23.1 & 25.0 & 25.6 \\
Protective & 20.9 & 22.8 & 23.4 \\
Distilled water & 5.5 & \\
DMSO & 2.6 \\
MMS & 49.5 \\
\hline Values are based on the average mean readings of MNPCEs on the two
\end{tabular}
doses which are insignificantly different from each other.

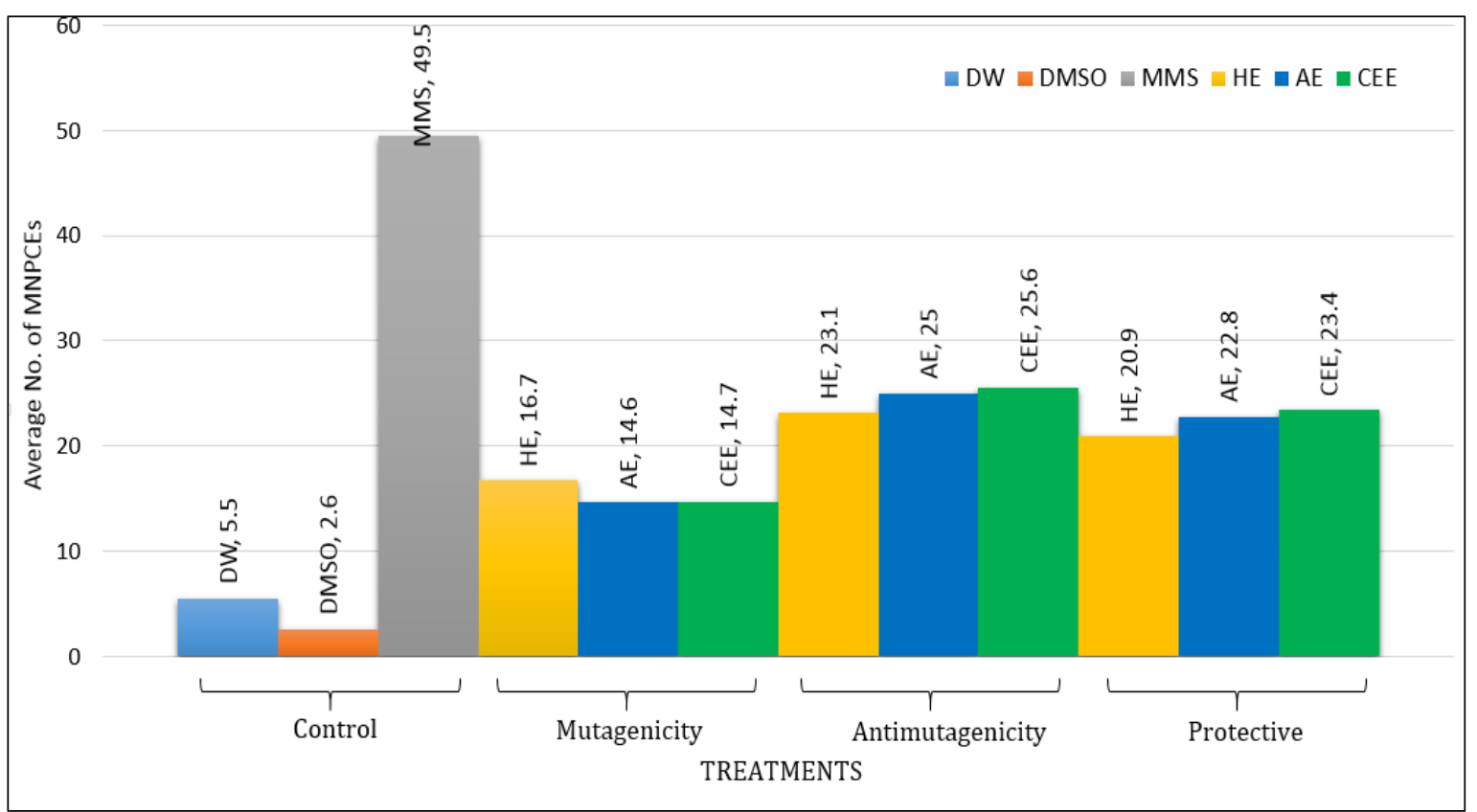

Fig. 1: Graphical representation of the number of MNPCEs per treatments. DW-Distilled Water, DMSO-Dimethyl Sulfoxide, MMS-Methyl Methanesulfonate, HE-Hexane Extract, AE-Aqueous Extract and CEE-Crude Ethanolic Extract

\section{Conclusion}

Phytochemical screening of Crescentia cujete Linn. leaves extracts showed presence of secondary metabolites. Flavonoids are present in aqueous, and ethyl acetate extract of Crescentia cujete Linn. Reducing sugar and tannins are present in all extracts of the plant. Steroids are present in hexane and ethyl acetate extracts. Aqueous extract of the plant is the only extract showing the presence of saponins. Clarkson Toxicity Index Reference shows that hexane, aqueous, and crude ethanolic extracts of the plant sample with high toxicity in brine shrimp Artemia salina having chronic $\mathrm{LC}_{50}$ of $0.0,0.184$ and $6.47 \mathrm{ppm}$, respectively. Micronucleus test of the plant extracts (hexane, aqueous, and crude ethanolic extracts) administered alone showed an increase in the occurrence of (MNPCE) compared to the negative control. However, compared to the positive control, plant extracts showed lower mutagenic activity. Treatment of the plant extract before and after induction of MMS showed significant reduction of the occurrence of MNPCE in mouse peripheral blood. Therefore, it can be deduced that all of the plant extracts of $C$. cujete Linn. namely namely: $\mathrm{HE}, \mathrm{AE}$, and CEE showed comparable mutagenicity, antimutagenicity and protective potentials towards
MMS probably due to the presence of the various phytochemicals like flavonoids, tannins, saponins, reducing sugars and steroids that could trap the $\mathrm{CH}_{3}$ carbocation released by MMS.

\section{Acknowledgement}

The researchers would like to thank Dr. Fema M. Abamo, Director of Research, Dr. Otinggue $M$. Masnar, Vice Chancellor for Research and Extension, Dr. Macapado A. Muslim, former President of Mindanao State University (MSU) System for approving this project and Dr. Habib W. Macaayong, President MSU System, Philippines for funding this research.

\section{References}

Arbonnier M (2004). Trees, shrubs and Liannas of West Africa dry zones. Margraf Publishers GMBH, Weikersheim, Germany.

Chukwuma ER, Obioma N, Christopher OI (2010). The phytochemical composition of some biochemical effects of Nigerian tigernut (Cyperus esculentus L.) tuber. Pakistan Journal of Nutrition, 9(7): 709-715.

Chung KT, Wong TY, Wei CI, Huang WY, and Linn Y (1998). Tannins and human health, a review. Critical Reviews in Food Science and Nutrition, 38(6): 421-464. 
Clarkson C, Maharaj VI, Crouch NR, Grace OM, Pillay P, Matsabisa MG, and Folb PI (2004). In vitro antiplasmodial activity of medicinal plants native to or naturalised in South Africa. Journal of ethnopharmacology, 92(2): 177-191.

Cooper GM (1993). The cancer book. Jones and Bartlett Publishers, Burlington USA.

Dong Q, Schlueter SD, and Brendel V (2004). PlantGDB, plant genome database and analysis tools. Nucleic acids research, 32(suppl_1), D354-D359.

Eder E, Favre A. Deininger C, Hahn H, and Kütt W (1989). Induction of SOS repair by monofunctional methanesulphonates in various Escherichia coli strains. Structure-activity relationships in comparison with mutagenicity in Salmonella typhimurium. Mutagenesis, 4(3): 179-186.

Egwaikhide PA, Okeniyi SO, and Gimba CE (2009). Screening for anti-microbial activity and phytochemical constituents of some Nigerian medicinal plants. Journal of Medicinal Plants Research, 3(12): 1088-1091.

Fenech M (2000). The in vitro micronucleus technique. Mutation Research/Fundamental and Molecular Mechanisms of Mutagenesis, 455(1): 81-95.

Finney DJ (1952). Probit analysis. $2^{\text {nd }}$ Edition, Cambridge University Press, New York, USA.

Frantisek S (1998). The natural guide to medicinal herb plants. Tiger Book International Plc, London, UK.

Hartwell G and Bellizzi R (1982). Clinical investigation of in vivo endodontically treated mandibular and maxillary molars. Journal of Endodontics, 8(12): 555-557.
Hemjadi M (2010). Introduction to cancer biology. Ventus Publishing, Holstebro, Denmark.

Komarova NL, Sengupta A, and Nowak MA (2003). Mutationselection networks of cancer initiation: Tumor suppressor genes and chromosomal instability. Journal of theoretical biology, 223(4): 433-450.

Lipkin R (1995). A larger role for RNA in life's emergence. Science News, 147(18): p. 279.

Meyer BN, Ferrigni NR, Putnam JE, Jacobsen LB, Nichols DJ, and McLaughlin JL (1982). Brine shrimp: a convenient general bioassay for active plant constituents. Planta Medica, 45(5): 31-34.

Morton JF (1981). Atlas of medicinal plants of Middle America: Bahamas to Yucatan. Charles C Thomas, Springfield, USA

OECD (1997). Guidelines for the testing of chemicals for a new guideline 474: In vitro mammalian cell micronucleus test (MNvit). Organisation for Economic Co-operation and Development, Paris, France.

Tiwari P, Kumar B, Kaur M, Kaur G, and Kaur H (2011). Phytochemical screening and extraction: A review. International Pharmaceutical Sciencia, 1(1): 98-106.

Vogelstein B, Fearon ER, Hamilton SR, Kern SE, Preisinger AC, Leppert M, Smits AM, and Bos JL (1988). Genetic alterations during colorectal-tumor development. New England Journal of Medicine, 319(9): 525-532.

Wang NS (2016). Experiment no. 4a glucose assay by dinitro salisylic acid colorimetric method. Department of Chemical and Biomolecular Engineering, University of Maryland, College Park, USA. 